\title{
Leaf Disease Analysis using Smart System
}

\author{
Jasmin.M, Sowmiya Manoj, Meenaa Kumari.M.
}

\begin{abstract}
The recognizable proof of infection on the plant is a vital key to keep a substantial loss of yield and the amount of horticultural item. The indications can be seen on the pieces of the plants, for example, leaf, stems, sores and natural products. The leaf demonstrates the indications by evolving shading, demonstrating the marks on it. This recognizable proof of the malady is finished by manual perception and pathogen discovery which can devour additional time and may demonstrate exorbitant. The point of the venture is to distinguish and group the infection precisely from the leaf pictures. The means required in the process are Preprocessing, Practicing and Identification. The sickness considered are Powdery Mildew, Downey Mildew which can make substantial misfortune paddy crop. For distinguishing proof of illness highlights of leaf, for example, real hub, minor pivot and so forth are separated from leaf and given to classifier for characterization.
\end{abstract}

Keywords : Catchphrases Leaf division ;python programming; information munging; ,efficient achievability; specialized plausibility, System testing; Blur Soften Image; Tesseract..

\section{INTRODUCTION}

Presently days, another idea of shrewd cultivating has been presented where the field conditions are controlled and observed utilizing oneself working frameworks. The self acknowledgment of the infection depends on the recognizable proof of the manifestations of ailment. So data about the sickness event could be rapidly and precisely given to the ranchers, specialists and scientists. This thus diminishes the checking of huge field by individual. In infection acknowledgment from picture the key is to separate the trademark highlight of the sick locale. As indicated by the malady the highlights may fluctuate.

The highlights those are extricated out from picture are color, sizes ,surface etc. Different times for location of the illness more highlights are removed and these separated element would build the equipment just as programming cost. This upcoming causes increment in the intricacy and the calculation duration. Thus it is important to lessen the component information. The event of the malady on the plant may result in noteworthy misfortune in both standard just as the amount of farming item.

It can deliver the negative effect on the nations whose profitables are principally subject to the farming. Thus

Revised Manuscript Received on August 22, 2019.

Jasmin.M Assistant Professor, Department of Electronics And Communication Engineering,, Bharath Institute of Higher Education and Research, Chennai, India. rifriz@gmail.com

Sowmiya Manoj, Assistant Professor, Department of Electronics And Communication Engineering,, Bharath Institute of Higher Education and Research, Chennai, India. sow_anu@yahoo.com

Meenaa Kumari.M. Assistant Professor, Department of Electronics And Communication Engineering,, Bharath Institute of Higher Education and Research, Chennai, India. meenumathi.m@gmail.com the recognition of the illness in the prior layers is imperative to stay away from the misfortune as far as quality, amount and money. Normally the techniques that are embraced for checking and the board of plant leaf sickness are manual. One such major approach is stripped eye perception. Be that as it may, the prerequisite of this strategy is persistent checking of the field by an individual having predominant information about the plants and its comparing ailments. In addition, selecting such an individual would may demonstrate expensive. Another methodology is looking for counsel from the master which may include the expense. Additionally, the master must be accessible in time else it might results in misfortune. Finding of ailment on plant should likewise be possible in research center testing. [15-20]

In any case, this strategy requires tasteful research facility conditions alongside expert learning. The pathogen identification techniques can give progressively precise outcomes. As the tests are done of field the expense might be high and could be tedious. This paper proposes a framework which can give progressively precise outcomes identified with the distinguishing proof and characterization of ailment. It attempts to supplant the need of the specialists to particular degree. Here, the caught picture is primarly implementing to rescale it and afterward changed over to HSI shading empty position by utilizing division. The highlights, for example, real hub, minor hub, unpredictability are extricated from the picture. In the last advance, these highlights are given to the classifier to characterize the sickness happened on the leaf.

\section{II.LITERATURE SURVEY:}

.Plant leaf illness observation and categorization based on $\mathrm{cnn}$ with lvq designing melike sardogan; adem tuncer; yunus ozen ieee 2018. The early location of illnesses is essential in farming for a productive harvest crop. The fungal area, late scourge, septoria leaf area and yellow bended leaf ailments influence the yield nature of crops. Programmed strategies for grouping of plant infections likewise help making a move in the wake of recognizing the side effects of leaf illnesses. This paper shows a Convolutional Neural Network (CNN) model and Learning Vector Quantization (LVQ) calculation depends strategy for crop leaf illness recognition and arrangement. The dataset having 500 pictures of crop leaves with four manifestations of infections. We have displayed a CNN for programmed include outcoming and grouping. Shading data is effectively utilized for crop leaf infection inquires about. In our region, the channels are connected to three channels dependent on RGB segments. The LVQ has been sustained with the yield highlight vector of convolution region to prepare the system. The trial outcome approve that the upcoming strategy adequately perceives four distinct sorts of crop leaf illnesses.

.Detection of leaf sicknesses and grouping utilizing computerized picture handling R. Meena Prakash ; 
G.P. Saraswathy ; G. Ramalakshmi ; K.H. Mangaleswari ; T. Kaviya IEEE 2018.

In this paper, picture handling procedures are utilized to identify the crop leaf infections. The goal of this time is to execute picture investigation and order strategies for location of leaf ailments and arrangement. The introduced system comprises of four sections. They are (1) picture preprocessing Segmentation of the leaf utilizing K-implies bunching to decide the infected regions (3) include outsourcing and (4) Classification of maladies. Surface highlights are separated utilizing factual Gray-Level Co-Occurrence Matrix (GLCM) highlights and characterization is finished utilizing Support Vector Machine (SVM).

Robotized image observing system for deep understanding-based crop plant leaf disease identifying and recognition machine g. de luna ; elmer p. dadios ; argel a. bandala ieee 2018. Savvy cultivating framework utilizing fundamental foundation is an inventive innovation that improves the purity and amount of agrarian creation in the nation with tomato crop. From tomato crop cultivating take contemplations from different factors, for example, condition, soil, and measure of daylight, presence of sicknesses can't be maintained a strategic distance from. The ongoing researches in PC vision made conceivable by profound grsping has made ready for lens-helped ailment analysis for tomato. This investigation built up the inventive arrangement that gives effective sickness identification in tomato plants. An engine controlled picture catching region was prepared to catch four sides of each crop plant to distinguish and perceive leaf infections. A particular type of tomato which is Diamante Max was utilized as the guinea pig. The framework was intended to recognize the infections in particular Phoma Rot, Leaf Miner, and Target Spot. Utilizing dataset of 4,923 pictures of sick and sound crop plant leaves gathered under actional conditions, we make a profound convolutional neural system to recognize some infections or nonappearance off. The framework utilized Convolutional Neural Network to distinguish which of the crop illnesses is available on the observed tomato plants. The F-RCNN prepared peculiarity discovery demonstrate delivered a certainty score of $80 \%$ while the Transfer understanding infection acknowledgment show accomplishes an exactness of $95.75 \%$. The mechanized picture catching framework was actualized in genuine and enrolled a $91.67 \%$ exactness in the acknowledgment of the crop plant leaf sicknesses.

.Svm classifier depends crop leaf illness location pranjali b. padol ; anjali a.yadav ieee 2018.

Grape establishes a standout amongst the most broadly developed natural product crops in the India. Profitability of grape diminishes because of contaminations brought about by different kinds of sicknesses on its natural product, stem and leaf. Leaf infections are fundamentally brought about by microorganisms, growths, infection and so forth. Maladies are a main consideration constraining natural product generation and sicknesses are frequently hard to control. Without exact illness conclusion, legitimate control activities can't be utilized at the fitting period. Picture happening is one of the generally utilized method is received for the crop leaf sicknesses identification and grouping. This paper is planned to help in the identification and order leaf sicknesses of crop utilizing SVM grouping method. Primarly the infected area is discovered utilizing division by $\mathrm{K}$-implies bunching, at that point both shading and surface highlights are extricated. At long last arrangement procedure is utilized to identify the sort of leaf ailment. The proposed framework can effectively distinguish and characterize the analyzed malady with exactness of $88.89 \%$.

\section{III.EXISTING SYSTEM:}

In present day, OpenCV is the most extensive open source library for PC vision and it has vast client network. OpenCV has substantially more capacities for PC vision than MATLAB. A considerable lot of its capacities are actualized on GPU. The library is as a rule persistently refreshed (a refreshed adaptation is discharged around each 3 to 4 months). All in all $\mathrm{C}++$ OpenCV code runs quicker than MATLAB code. OpenCV has a bigger number of capacities for PC vision than MATLAB. A large number of its capacities are executed on GPU [3]. In like manner $\mathrm{C}++$ OpenCV code runs quicker than MATLAB code however when contrasted with OpenCV C++ OpenCV python is vastly improved than the $\mathrm{C}++$, python is a superior and less demanding than the other programming language like $\mathrm{C}++$. In $\mathrm{PC}$ vision, we are looked with comparative decisions. Which apparatus should a $\mathrm{PC}$ vision engineer/developer learn - OpenCV utilizing $\mathrm{C}++$, OpenCV utilizing Python, or MATLAB, with respect to the present we have a couple of choices to browse. Before in past there were nothing worth mentioning libraries for PC vision. We become acquainted with about these examinations by related books which were accessible and begun coding own smaller than usual library of PC vision calculations [6].Like MATLAB, OpenCV was likewise made for Image preparing and utilized as option and a lot quicker device than the other reproduction forms. Each bundle in OpenCV, the capacity and information structure were planned with the Image Processing coder. MATLAB, on the opposite side, we get nearly everything without exception on the planet as tool stash. Despite the fact that MATLAB is a generally simple language to get to holds with, this abnormal state scripting language, turns out to be slower now and again. In such cases, OpenCV works better and delivers exact outcomes. Memory the board or some other low-level programming issues. Moreover, it tends to be anything but difficult to deal with some code to model your picture preparing thought. To peruse in a picture from document and show it. One of the eminent commitment of the open source network to the logical world is Python.

To begin with, different successive LR tag casings of a similar scene are taken as the information perceptions. Second, the successful picture enrollment is done to acquire exact movement parameters between the LR input pictures, which is our primary core interest. Third, the picture recreation is actualized to get a HR remade picture [7]. Exact picture enrollment is of fundamental significance for the accomplishment of SR strategies. On one hand, the recurrence approach proposed by P.Vandewalle in [5] beats past recurrence techniques and some spatial space strategies. It works especially well on pictures with solid recurrence content in various ways, and it fulfills the subpixel precision in the bigger interpretation and turn estimation [8].

In any case, Vandewalle's calculation has the lack that it expect movement demonstrate contains just pivot and interpretation, which leaves the scaling development unsolved. [9] This enrollment calculation is basically utilized 
for tag picture SR remaking, we may get an obscured HR picture, which can be seen from the exploratory outcomes[10]. Then again, the great FMT calculation, for the most part utilized in picture mosaic [7], can execute scaling, pivot and interpretation estimation between casings, however it is just on the number pixel level, which can't meet the prerequisites of SR for tag picture. On the base of above investigation, a novel recurrence space enlistment technique is proposed.

\section{IV.DISADVANTAGES OF A EXISTING SYSTEM:}

1. Poor image resolution.

2. Less Accuracy

3. Poor lighting and low differentiation

4. Higher Computational Cost

5. Absence of guidelines of the plate of the vehicles

6. Inappropriately sectioned characters will result in misrecognized characters..

\section{V.PROPOSED SYSTEM:}

The initial step is to get pictures of different leafs from the Digital camera or any source. There are different picture preparing procedures connected to distinguish the infection. Picture handling is utilized to get helpful highlights that can demonstrate critical for further procedure. With picture preparing, SVM and k-implies is additionally utilized, k-implies is a calculation and SVM is the classifier. At that point next different procedures are to use to get and result close by. Flowchart demonstrates the stream of the proposed framework and the vision subordinate discovery calculation. The underlying advance is to get the example pictures of the considerable number of leaves from the camera. [8]

The stream of the procedure of the proposed framework:

1) Input Image.

2) Blur Soften Image.

3) Changing over the information picture from RGB to HSV position.

4) Color Thresholding.

5) Separating the Foreground and the Background.

6) Leaf segmentation.

7) Feature Extraction of the leaf.

8) Disease recognition using SVM and K-means.

9) Desired result.

\section{VI.ADVANTAGES OF PROPOSED SYSTEM:}

1. High output efficiency.

2. User friendly.

3. Less time consumption.

4. User friendly.

5. Characters can be recognized correctly.

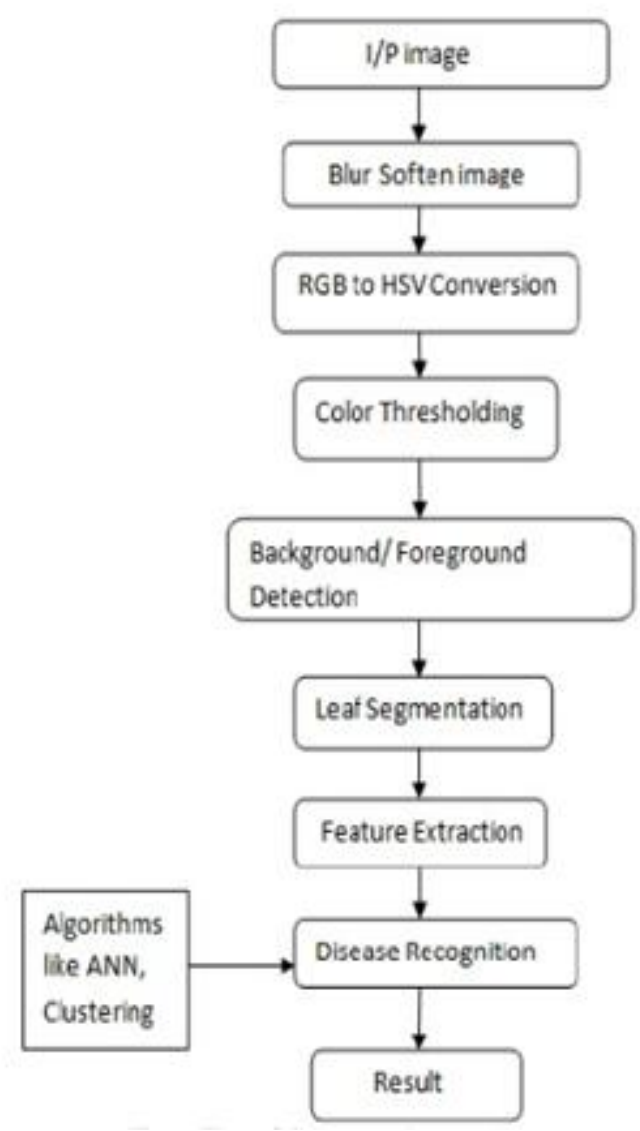

\section{VII.SYSTEM CONFIGURATION AND DIAGRAMS SYSTEM CONFIGURATION SOFTWARE REQUIREMENTS:}

- $\quad$ Operating System

: Windows 7

- Technology : python

- Web Technologies :Html,JavaScript,CSS

- IDE :Netbeans

- Web Server : Tomcat

- Database : MySQL

- Java Version : J2SDK1.5

\section{VIII.HARDWARE REQUIREMENTS:}

- Hardware

- Accuracy

- RAM

- Hard Disk

- Key Board

- Mouse

- Screen

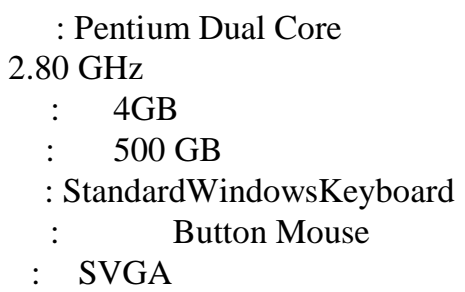

\section{IX.CLASS DIAGRAM:}

Class Diagram is the formal structure square of item situated outsorcing. It is used for both normal estimated visioning of the efficient of the formatt and furthermore for the nitty gritty lecture prepared an interpretation of the types into source code. Class formats can similar to be used for document presentation. The classes in a class chart can talk to both the basical things as well as communications in the implementation and the articles to 
be modified. In the class outlines these classes are talken to with the crates which having some sections. [9]

The tooper region holding the name of the class

The mid region holding the properties of the class

The bottom region gives the ideas or tasks of the class which can perform or attempt. [10]

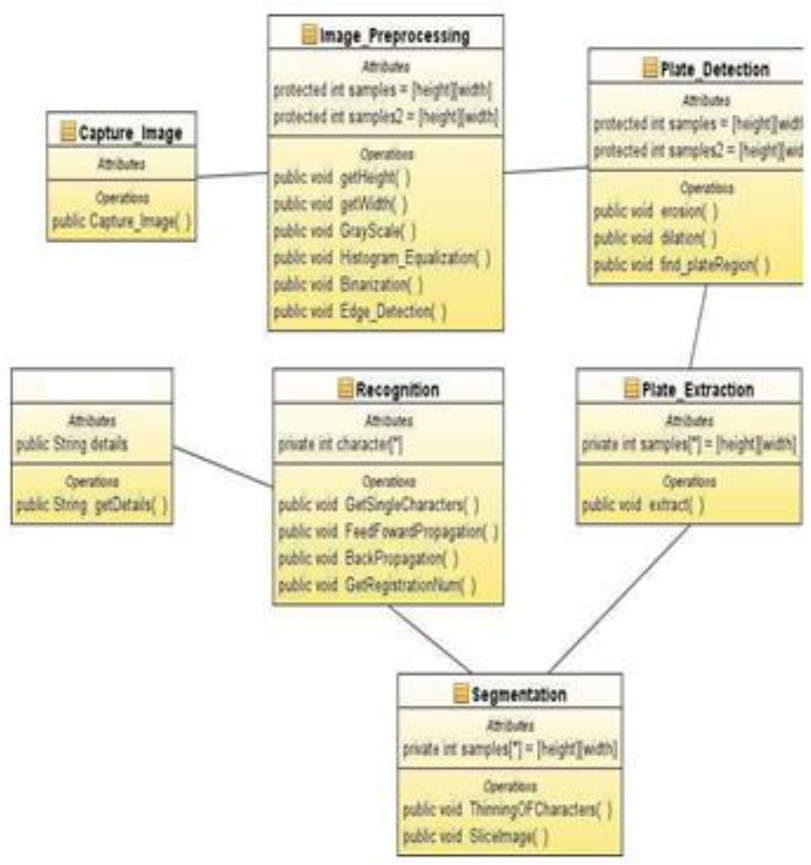

\section{X..SYSTEM TESTING:}

The purpose for trying is to invent problems. Trying is the process toward endeavoring to discover one probable thing or shortforming in a exertion thing. It returns an outcome to confirm useness of things, sub materials, congregations or potentially a fullfiled article the process toward making coding through the goal of ensuring practical outcome satisfies its requirements and customer wants and may not blasted in an unacceptable way. There are many various sorts of test. Each test type tends to a particular testing prerequisite. [12]

\section{XI.TYPES OF TESTS:}
A.Unit test:
Unit testing may have the structure of practices that accepts that the inward program rationale is processing appropriately, and that equipment inputs produce substantial crops. All deparments and inward code result ought to be accepted. It is the happening of personal programming units of the materials .it is happened after the completion of an individual unit approach combines. This is an essential thing, that relies upon data of its improvement and is prominent. Unit tests perform basical tests at part level and test a individual business procedure, application, as both as framework management. Unit tests confirms that every thing of a proper way of a perfection matters how works on precisely to the outcoming possibilities and having plainly specified sources of info and anticipated results. [13]

\section{XII.BLENDING TESTING:}

Blending experiments are designed to examine the organization of programming sections in order to verify how much they really keep going as one program. Screening is motivated by celebration and is increasingly concerned regarding the current official results of visions or crops. Mutual comprehension tests show that, despite the fact that the sections were separately fulfilled, as seen by rapid unit testing, the mixture of concentrations is correct and common. Mix screening is explicitly gone to unprotect the issues that arise from the section unit.[11]

\section{XIII.FUNCTIONAL TESTING:}

Real tests returns exact exhibitions that maintains practice are reachable as mentioned by the commercial and featured requirements, outline work material, and resultant guides.

Utilitarian testing is concentrated on the complementary maerial:

Acceptable Input : understanding classes of considerable maters must be recognized.

Unacceptable Input : distinguished things of invalid matter must be rejected.

Scope : scope must be proved returns the outcome.

Yield : recognized classes of utilization yields must be worked out.

Frameworks/Procedures : interfacing outworks or process must be summoned.

Team management and planning of practical tests is fighured around prerequisites, key possibilties, or extraordinary practices. What's more, methods inclusion comparing to identifying the Business process forms; matter crops, guessing methods, and enlightened process must be measured for confirming. Before useful analysis is compled, further performs are eminent and the dominant assessment of present trials is completed. [14]

\section{XIV.SYSTEM TEST:}

System screening confirms that the entire team's computing structure connects the requirements. It requires a configuration to guarantee that the findings are clear.. The design-based structure mix test is one of the primary job tests. The framework method carries out the process of representations and operates, underlining the performance of especially post-driven procedure and the conciliation observations.

\section{XV.TESTING WHITE BOX:}

White Box Testing is a process in which the object scanner understands, or is likely to be convincing, about the operation, framework and language of the object. It's a reason. It is used to test domains that can not be ideal from the point of disclosure. 


\section{XVI.TESTING OF THE DISCOVERY:}

Discovery Screening will be performed on an object without adequate guidance on the inner operations, format or language of instance being practiced. Finding studies, since many distinctive kinds of stuff, must be complicated by a conclusive source record., For instance, keeping or pre-requisite archive, for each report on the determination or specifications. It's an attempt in the item that comes to the test is achieved as a revelation. We can't "see" it. The outcome provides sources of information and responds to crops deprived of thinking about how the material works.

\section{XVII .UNIT-TESTING:}

Unit testing is normally conducted as a key feature of the combined code and unit test duration of the material life span, despite the realistic features that it is not remarkable for the performance and unit testing to be conducted as two specific layers.

\section{XVIII.TEST STRATEGY AND APPROACH:}

Surface results will be calculated to be physical, and checks written in exactly the same way.

\section{TEST OBJECTIVES:}

- Entirely all matter requirements must performs legitimately.

- Records The differentiated perfections must be implemented.

- The entry layout, texts and responses must not return to be conceded.

\section{XIX.FEATURES NEED TO TESTED:}

- Confirms that the segments are of ideal leadership • No matter how the passages should be confirmed - All the improvements should bring the individual to the ideal page.

Confirming the reconciliation of programming is a step-by-step test of at least some integrated programming components at the ideal point to produce improper stuff caused by outsorcising abandonment.. The undertaking of the joining test is to visible that parts or outsourcing applications, for example parts in a item framework or - one proper up programming applications at the perfectional levels communicate not with mistake.

All the performances referenced above passed effeciently. No imperfections practiced.

\section{B.Acceptance testing:}

Client Acceptance checking is a layout section of any undertaking and maintains noteworthy caluclates by the end performs. It additionally confirms that the layout meets the utilitarian requirements.

\section{C.Test outcomes:}

All the practices referenced above explicts effectively. No imperfections practiced.

\section{XX.CONCLUSION:}

The utilization of mechanized observing and the board frameworks are increasing expanding request with the innovative progression. In agrarian field loss of yield fundamentally happens because of boundless of infection.
Generally the recognition and distinguishing proof of the ailment is seen when the sickness advances to serious stage. Accordingly, causing the misfortune as far as yield, time and cash. The proposed framework is fit for distinguishing the ailment at the prior stage when it happens on the leaf. Subsequently sparing the misfortune and decreasing the reliance on the master to a limited degree is conceivable. It can give the assistance to an individual having less information about the illness. Contingent upon these objectives, we need to remove the highlights relating to the illness.

\section{REFERENCES}

1. Kongkham, D. \& Sundararajan, M. 2019, "Distributed wideband sensing method for faded dynamic spectrum access", International Journal of Innovative Technology and Exploring Engineering, vol. 8, no. 10, pp. 4309-4312.

2. Balaji, S., John Paul Praveen, A. \& Mohanraj, R. 2019, "Recognizable proof and analysis of palm print in biometric authentication system using bayes techniques", International Journal of Innovative Technology and Exploring Engineering, vol. 8, no. 9 Special Issue 3, pp. 1126-1129.

3. Kavitha, G., Priya, N., Velvizhi, R. \& Allin Geo, A.V. 2019, "Parallel computation in correspondence and signal processing", International Journal of Innovative Technology and Exploring Engineering, vol. 8, no. 9 Special Issue 3, pp. 1136-1139.

4. Hema, R., Sundararajan, M. \& Balaji, S. 2019, "Smartphone control robot with automatic firing gun", International Journal of Innovative Technology and Exploring Engineering, vol. 8, no. 9 Special Issue 3, pp. 625-627.

5. Kaliyamurthie, K.P., Sundar Raj, B., Velvizhi, R. \& Shanmugapriya, K 2019, "Dual band paper substrate CPW antenna for wireless applications", International Journal of Innovative Technology and Exploring Engineering, vol. 8, no. 9 Special Issue 3, pp. 605-608.

6. Geo, A.V.A., Arunachalam, A.R., Michael, G. \& Elankavi, R. 2019 , "Evaluating architecture using compact modalities", International Journal of Innovative Technology and Exploring Engineering, vol. 8, no. 9 Special Issue 3, pp. 836-838.

7. Theivasigamani, S., Jeyapriya, D. \& Anita Davamani, K. 2019, "Anamoly analyzing and exploring for wireless sensor networks", International Journal of Innovative Technology and Exploring Engineering, vol. 8, no. 9 Special Issue 3, pp. 1116-1118.

8. Jeyapriya, D., Theivasigamani, S., Velvizhi, R. \& Nandhini, P. 2019, "Program detection in wireless feeler networks", International Journal of Innovative Technology and Exploring Engineering, vol. 8, no. 9 Special Issue 3, pp. 1194-1195.

9. Gowri Sankaran, B., Karthik, B. \& Vijayaragavan, S.P. 2019, "Image compression utilizing wavelet transform", International Journal of Innovative Technology and Exploring Engineering, vol. 8, no. 10, pp 4305-4308.

10. Gowri Sankaran, B., Karthik, B. \& Vijayaragavan, S.P. 2019, "Weight ward change region plummeting change for square based image huffman coding", International Journal of Innovative Technology and Exploring Engineering, vol. 8, no. 10, pp. 4313-4316.

11. Hema, R., Sundararajan, M. \& Balaji, S. 2019, "Smartphone control robot with automatic firing gun", International Journal of Innovative Technology and Exploring Engineering, vol. 8, no. 9 Special Issue 3, pp. 625-627.

12. Rangaswamy, K. \& Rajabhushanam, C. 2019, "Congestion control in wireless network using TCP friendly rate control (TFRC)", International Journal of Recent Technology and Engineering, vol. 8, no. 2 Special issue 3, pp. $1598-1602$.

13. Tamil Selvan, S. \& Sundararajan, M. 2019, "Performance Parameters of 3 Value $8 \mathrm{t}$ Cntfet Based Sram Cell Design Using H-Spice", Internationa Journal of Recent Technology and Engineering, vol. 8, no. 2 Special issue 5, pp. 22-27.

14. Vinoth, V.V. \& Kanniga, E. 2019, "Steganographical techniques in hiding text images - system", International Journal of Recent Technology and Engineering, vol. 8, no. 2, pp. 6535-6537.

15. Saravana, S., Balaji, S., Arulselvi, S. \& John Paul Praveen, A. 2019, "Reliable power quality monitoring and protection system", International Journal of Innovative Technology and Exploring Engineering, vol. 8, no. 9 Special Issue 3, pp. 644-645. 
16. Sundaramoorthy, A. \& John Wiselin, M.C. 2019, "Single patch antenna with multiple feed", International Journal of Innovative Technology and Exploring Engineering, vol. 8, no. 9, pp. 1743-1747.

17. Velavan, R., Bharanidharan, S. \& Sheeba, B. 2019, "EMF pollution Causes, effects and protection", International Journal of Innovative Technology and Exploring Engineering, vol. 8, no. 9 Special Issue 3, pp. 1166-1168.

18. Veer, R.A., Arulselvi, S. \& Karthik, B. 2019, "Construction of ensemble square classification approaches in MIMO OFDM", International Journal of Engineering and Advanced Technology, vol. 8, no. 5, pp. 2039-2041.

19. Agitha, W. \& Kaliyamurthie, K.P. 2019, "Improved energy efficient in WBAN using MAC with cloud computing", International Journal of Innovative Technology and Exploring Engineering, vol. 8, no. 8, pp. 2405-2408.

20. Kastro, G.G. \& Wiselin, M.C.J. 2019, "Design and analysis of stub loaded resonator", International Journal of Recent Technology and Engineering, vol. 8, no. 1 Special Issue4, pp. 272-283.

\section{AUTHORS PROFILE}

Jasmin.M Assistant Professor, Department of Electronics And Communication Engineering,, Bharath Institute of Higher Education and Research, Chennai, India..

Sowmiya Manoj, Assistant Professor, Department of Electronics And Communication Engineering,, Bharath Institute of Higher Education and Research, Chennai, India.

Meenaa Kumari.M. Assistant Professor, Department of Electronics And Communication Engineering,, Bharath Institute of Higher Education and Research, Chennai, India. 